\title{
A Study of Smart Lighting in Smart Cities
}

\author{
Xiangyuan Guo
}

Department of Physics, Hong Kong Baptist University, Liuzhou 545000, Guangxi Province, China

\begin{abstract}
With the rapid development of science and technology, people gradually realized that intelligent lighting can also be applied in smart cities. This paper briefly introduces the functions of intelligent lighting and the benefits it can bring to smart cities, and also predicts its possible future development.
\end{abstract}

Key words: Smart lighting; Smart cities; 'Five remote'

Publication date: April, 2021; Publication online: 30 April, 2021

*Corresponding author: Xiangyuan Guo, 1743443241@qq.com

\section{Introduction}

The $21^{\text {st }}$ century, is a technology explosion age as tons of new technologies emerged. Among all these technologies, some of them has significantly impacted our daily life, such as computer technology, communication technology and automatic control technology, etc. With these developed and mature technologies, our society has become more and more intelligent. Meanwhile, smart lighting technology showed up, bringing more convenience to our lives.

Before knowing about the benefits of smart lighting, you should know what the smart lighting is. Smart lighting, a kind of technology developed based on computer technology, wireless communication data transmission technology and smart information processing technology, is able to intelligently controls light equipment, in an attempt to create a new, comfortable and convenient method of offering a better environment in our daily life and work.

\section{Application of smart lighting in smart cities}

In 2007, EU first proposed the concept of smart cities. Then, IBM company brought a new idea of 'Smart Earth' on 2008 Annual Forum in November when smart cities really started to attract people's attentions. In 2012, the ministry published an announcement about developing the national smart city pilot work, our country also disclosed the total number of pilot work, about 209. The 13th Five-year Plan also put forward to strengthen the construction of modern information foundation, promote big data and internet development. Building smart cities means higher requirements for smart lighting system. The other way around, the advanced smart lighting system technology can also promote the development of smart cities. So, it's a win-win strategy.

\section{Smart city lighting monitor system}

At present, based on the original imperfect 'three remote' and 'five remote' system and the location information system platform, a dynamic smart lighting monitor system has already entered the filed of smart lighting by applying big data, cloud calculation and internet technology. Intelligent city lighting monitor system is a complicated system which applies an advantaged communicate method, computer internet technology, automatic control technology and automatic detection technology, it can control and manage city road lighting instantly and accurately. Intelligent city lighting monitor system is supposed to be capable of remote detecting, remote communicating, remote controlling, remote regulating and remote inspecting, in order to finally not only accomplish automatic detection, feedback and alarm as well as data collection, statistics and analysis functions.

3.1 Remote detection, remote communication functions

Intelligent city lighting monitor system necessarily has powerful function of sensing and detecting, as it is an important symbol that lighting system intelligent level already got improved. Sense and detection system is consisted of a lot of different senses functions that work 
together and continuously to detect and collect the data in streetlamp area like real time voltage, current, states of contactors, active power, reactive power, power factors and electricity consumption. And then the data is sent back through the power line carrier communication technology, ZigBee communication technology, UWB carrier-free communication technology, and so on. Finally, these feed back data is sent to the remote controlling and management center, and then the analyses on the working situation for each areas and each streetlamps to master the reality power is performed, the numbers of turn on or turn off the switch, intensity of illumination, open or light lamp rate and saving electricity resources information.

\subsection{Remote controlling function}

By employing the smart lighting monitor system, can achieve the remote control in streetlamps switches, luminance control and lighting time. According to different management requirements, adopting different controlling modes such as time controlling mode, light controlling mode, pressure controlling mode, voice controlling mode and side road mode, etc. For example, put the time of switching lamp into the database, according to the longitude and latitude, seasons, holidays, and different situation on weather to achieve the so called 'time control', which can automatic timing control streetlamps in night light mode or half night light mode, the manage people can also point at some specific situations of one switch or more switches to switch control, by using different ways like single light, grouping, partition, city switch and so on. It also can base on the change of seasons and weather to make 'pressure control' or 'lighting control', power under some special condition like weather or time can be adjusted by the controller through the sub-stations, so that we can change the luminance intensity of streetlamps to achieve the goal of 'lighting control'. Or by adjust the voltage and current to improve extra power consumption in line load caused by voltage fluctuation and achieve the goal of 'pressure control' energy saving. It can not only reduce the electricity power consumption but also extend the lifetime of streetlamps. Besides, it can feedback some information to remote controlling and management center according to sensors on the public roads to response the voice and speed for vehicles and pedestrians. So that the center can make a decision on whether turn on or turn off the streetlamps, the numbers of these and illuminance intensity, finally to get the goal of intelligent management.

\subsection{Remote regulation and remote view functions}

For detecting a scene of information and data it can transfer to the remote control and management center with the location information system and global positioning system related to the hardware and software, finally achieve the remote scheduling for smart cities lighting equipment parameters. Through some remote monitor or others related to communication to achieve the real time observation, and also under the support in technology to develop more 'in-deep' photos analyse so that it could give more and more data supporting for automatic lighting managements.

\subsection{Automatic detection, feedback and alarm functions}

Send some controlling commands through the remote control and management center, focus on controlling center on each streetlamps real time monitoring and make a round in the area. If there is something wrong, it could feedback the data to remote controlling and management center in some communication ways, and attract the attentions by flashing the figure to alarm. With the location information system, the fault point area's information could be quickly show and then the remote controlling and management center working people will contact the related maintenance people to handle this. This can not only improve the efficiency on detecting and reduce the intensity on workers but also decrease the responding time for the whole streetlamp system and improve the ability on dealing with the emergency.

\subsection{Data collection, statistics and analysis functions}

Smart cities based on the internet, big data and cloud platform foundation, require make full use of information and communication technical measures to detect, analyze and integrate the key information in the core system for city working. Lighting system which around the city you can find anywhere also can be the biggest and most convenient data collector for the big city, and play a bed rock role for the smart cities. And form the technology side, through installing the detection and sense terminals on each streetlamps, the information within the detection area of this streetlamp can be easier collected, so that the smart streetlamp can provide the first hand data for city management. Through the analysis and integration for a lot of data, we can find some unusual rules form the city working, which can offer the scientific and accurate data source to analysis the result, so that it can better work for smart cities management. But because of the diversity of collecting data and refer to a lot of complicated management 
departments. So at present there still have a big problem on the information sharing. In a certain range it also need help of manager of this city to boost the overall programme in building the intelligent city and promote each management departments work and develop together like a family.

According to a new report, there are some cities have already started the building work on smart lighting controlling system, the most famous is the Beijing city lighting management center monitor system, it can tracks the sun light, detection about the weather condition, monitoring the urban natural illumination in remote and transport some video in remote within the global range. Also can detect the status of city lighting power supply and streetlamp facilities physical status in remote, so that some dynamic data can be gotten like facilities working status, capital status, environment condition and energy saving procession to achieve high efficiency city lighting management. With the accelerate boost on smart cities building processing, smart lighting controlling system can have a deep develop, improve and perfect in our country.

\section{The important role smart lighting playing in smart cities}

The concept of smart city just lately proposed, so most of building procession is at the beginning, and the important role of intelligent lighting is mainly showed in the following three ways.

\subsection{Smart lighting can provide the data base on building smart cities.}

In the construction of smart cities, whatever the smart government affairs, intelligent transportation or other related system, the most important and core content is to use the data exchange to make some decisions. Because the smart lighting system have important ability on integrated dealing matters and collecting the information on terminal which can give the support for data collection on smart cities. With the fast development of internet, people can make use of internet to monitoring some dynamic data in real time. So the mart lighting system can detect the complicated parameters in the scene. And make full use of the sensors in optical, radar, voice, electricity energy, photos, weather conditions to detect some hardly parameters change such as the traffic flow, the illuminance of the surroundings, decay of lighting, weather conditions, brightness of background, voltage fluctuations and etc. And then using the internet to translate the date into the application, so that it can provide some in time and efficient date on making scientific decisions. For example, by using the LED or OLED streetlamp monitoring system can get the fault information accurately, and pass by the department for streetlamps management to reduce the cost of fix the streetlamp. It can also use the data to link with the traffic light system to help as adjust function so that can achieve the traffic bypass flow in the busy time, finally it can provide the support for construction, improving and perfecting the smart transportation.

\subsection{Smart lighting can bring some benefits for society in environment, economy, social and so on.}

\subsubsection{Environmental benefits}

Lighting productions would cost a large amount of energy during making, transporting, using and dying, but with the fast developing of technology the update rate of lighting productions is also accelerating. At the same time, electricity energy consumption in the city increasing a lot rapidly, this also cause a large amount of carbon dioxide emissions which would directly influence people living environment. Smart lighting in the city can not only boost the development of new lighting productions, which can make the lifetime longer and longer, have better lighting effect, and with higher efficient but also can through the intelligent monitoring system to achieve the controlling on smart energy saving so that reduce the consumption on energy efficiently, reducing the pollution to the environment, finally produce a considerable environment benefit.

\subsubsection{Economy benefits}

Smart lighting system can achieve the city lighting streetlamp in one way controlling and management, the energy saving effect is obvious. Some scientists do a research about smart lighting management, it shows that the power saving rate could reach or more than $30 \%$. If we consider the city level city have 30,000 streetlamps, the average power is $250 \mathrm{~W}$, the average lighting time in a year suppose is about 4000 hours and the energy saving rate estimate in $30 \%$. So it is easily to calculate saving energy is about $30,000 \times 250 \times 4,000 \times 30 \%=9,000,000 \mathrm{~kW} \cdot \mathrm{h}$, it means that can saving the energy consumption in electricity about $7,000,000$ RMB. However, in the point of view in city lighting environment, it is not a small charge for manual inspection and management maintenance. Smart lighting monitor system can let the manager clearly know the statues of each streetlamps in every block, finding the broken streetlamp and send professional to repair and maintain it, so that the cost of maintaining the lighting facilities can be reduced, the lifetime of lamp can also get extend. 


\subsubsection{Social benefits}

Smart lighting can achieve the city lighting goals in integrated good management, real time detection alarm, predict the fault may happened, deal with the dangerous matter in time, handle the problem in processional and improving the efficiency on processing, so that the level of city lighting management can get a great improvement. It can also make sure the serve quality on city lighting side, reach the goal like responding lighting, beautifully lighting, safety lighting, improving the environment for people living, raising the transportation and social security safety, fully shows the public sever level and finally get to the last mission: improving the brand image of the whole city.

\subsection{Smart lighting can promote the innovation and} development of smart cities building models.

City roads lighting play an important role in the public works, the building money mostly come from the government financial funds. Remake engineering for the city smart lighting can use a financial models which called PPP (public-private-partnership), to enhance the teamwork with social finance. During the procession of construction, the company which has the proprietary technology would award an energy management contract with government project implementation department, signing a financial agreement with financial groups, also responded for offering the technical support and designing for the whole engineering, construction and operation service.

\section{Future development ways on smart city lighting}

After I talk about so many functions and benefits on the smart lighting, It's time to show my opinion for the smart lighting future. After I read some literature related to this part and found some information from the internet, I though the future development in smart lighting can be divided into two parts. The first one is traffic monitoring, secondly is environment monitoring. You may feel worried about that is these parts, I need to remind you what is the final goal for smart lighting. Creating a convenient experience for users? Or building a comfortable living environment? Both are right, but too small. In my point of view is creating a smart city or to make a bigger aspect, building a smart planet. I know that it sounds crazy, tut dreams always have to be, so that we can push forward, right?

We all know people and goods free movement is the important part in the city, but different city have different conditions. For example, in some cities the traffic jams only happened in the rush hour, and in other cities it seems that never stop. Although the intensity in transportation is not the same in every area, but the requirement for cities people is always the same. No matter what city we are in, when you are driving on the road or just waiting the traffic lights behind the zebra crossing, we want the same thing : smooth traffic condition. I have to say we are luckily can live in the technology fast developing society, the traffic problem can be solve with the technical help. With the development of new sensor applications which are installing with the streetlamp, traffic flow can get into a new level. Nowadays, our city can crate a safe and inclusive transport experiences by using ICT and internet as pilots. By applying more and more sensors to integrate the smart city lighting system, so that cities can improve the roads and traffic conditions more efficiently by transportation monitoring and management.

Traffic jam on the road already made a big impact on the environment and life quality. This problem would not disappear naturally, normal government choose to rebuild the road to raise the driving capacity. But it is very expensive, and usually impossible in density populated area. Of cause, a better choice is to encouraging the driver to choose another route which is alternative. But it is also not possible without think over the existing traffic situation. So I want to introduce a useful way to solve this problem which is very popular in mainland map applications. The 'real time map', which is a sensor solution based on monitoring traffic density and shows the timely data to drivers on the map application. By using this 'real time map' you could enjoy the following benefits: (1) Stay information: Keep your eyes on the road and make some decisions based on timely data. (2) Ease traffic: For many people, going out is a daily activity.Citizens are encouraged to choose the routes and times are in smooth condition by telling them about the real situation of transportation. (3) Collecting data: The accumulated data can be statistically analyzed to better understand road conditions and traffic in the year. (4) Plan roadworks

By analyzing the 'real time map', it is possible to predict the location of roads and time that need to be maintained mostly.

At last I want to talk about probability on this special map in traffic:

(1) Improve and perfect the traffic flow

For example, with the help of streetlamp monitors when coordinating a series or on a large straight line of 
traffic lights on the same road turning into green, we can create a so-called "green flow" which can allow this group of cars to pass so that these cars do not need to stop at an intersection. In this way, cities can deal with more load on traffic condition and also reduce the energy consumption. According to the lesson PHYS7420, we know that if cars take a break so frequently, It would cost a lot of energy compared to continue driving. And this idea is not just on the paper, it's possible. The technical worker just need to make a collection of the traffic data from the sensors on the streetlamp so that it can be integrated on top of the lights along the road to adjust the traffic light as I said.

(2) Analyze and help

The detecting sensors on the streetlamp shows the infinity probability on traffic analyze and management. When the traffic accident happen, the sensor can detect the location which cause the traffic slowdown and disruption. When these information are detected by the sensor, it would send the information the traffic management center and also sent out a warning by the 'real time map' to drivers so that these drivers can choose the alternative route in time. At the same time, an ambulance or emergency services can be called based on the information collecting by the sensors on the streetlamp.

(3) Improve working conditions and save lives

We all know that the traditional traffic management system rely too much on the workers. What a pity, it is also a dangerous work. Because traffic police or traffic controlling worker need to work in different weather conditions whatever in hot or cold days and even at midnight you still have chance to see them working in their position. So it's also have a relatively higher probability to knocked down by cars. Even though these dangers make them work carefully, but accidents will always happen. Especially when constructing on the road, this possibility is bigger because the road becomes narrowed. So that's what I want to avoid, by using the technology and sensors on the streetlamp like I mentions, to reach the goal on reducing the casualties for these worker.

\section{Conclusion}

In addition to the application of smart lighting in outdoor smart cities as mentioned in the article, smart lighting can also be shown in smart home, and the current market response also shows that smart lighting is extremely excellent. And with the progress of science and technology, smart lighting, as mentioned in the article, will not only be lighting, but more fields of combination and utilization. Let's look forward to the bright and promising future of the smart lighting.

\section{References}

[1] Nefedov E, Maksimainen M, Sierla S, et al. Energy efficient traffic-based street lighting automation[J]. IEEE International Symposium on Industrial Electronics, 2014:1718-1723.

[2] Afshari S, Mishra S. A plug-and-play realization of decentralized feedback control for smart lighting systems[J]. IEEE Transactions on Control Systems Technology, 2016, 24(4):1317-1327.

[3] Zhang Y, Zhang Y. Discovering user mobility and activity in smart lighting environments. 2016.

[4] Beccali M, Bonomolo M. Special issue "smart urban lighting systems"[J]. Applied Sciences, 2020, 10(10):3627.

[5] Sun B, Zhang Q, Cao S. Development and implementation of a self-optimizable smart lighting system based on learning context in classroom[J]. International Journal of Environmental Research and Public Health, 2020, 17(4).

[6] Giovanni M, Dario B, Salvatore D, et al. A smart city lighting case study on an openstack-powered infrastructure[J]. Sensors, 2015, 15(7):16314-16335.

[7] Petritoli E, Leccese F, Pizzuti S, et al. Smart lighting as basic building block of smart cities: An energy performance comparative case study[J]. Measurement, 2019, 136:466-477.

[8] Huang Z. Parameter Adaptive Multimodal Optimization and its Application in Smart Lighting[D]. Rensselaer Polytechnic Institute. 2013.

[9] [9] Sevincer, Abdullah, Bhattarai, et al. Lightnets: smart lighting and mobile optical wireless networks -- A survey[J]. Communications surveys \& tutorials, 2013.

[10] Dong F. Dynamic Adaptive Sampling for Environmental and Smart Lighting Distributed Sensor Applications[M]. Rensselaer Polytechnic Institute, 2012.

[11] Afshari S. Feedback control of smart lighting systems based on color science[D]. Rensselaer Polytechnic Institute. 2015.

[12] Beccali M, Bonomolo M, Galatioto A, et al. Smart lighting in a historic context: a case study[J]. Management of Environmental Quality An 
International Journal, 2017, 28(2):282-298.

[13] Castro M, Jara A J, Skarmeta A. Smart lighting solutions for smart cities[C]. International Conference on Advanced Information Networking \& Applications Workshops. IEEE Computer Society, 2013.

[14] Jia L. Range sensing and environmental simulation for smart lighting applications[J]. Dissertations \& Theses Gradworks, 2014.

[15] The difference between intelligent lighting design and traditional lighting design $[\mathrm{J}]$. Electrical Technology of Intelligent Building, 2015(02):78-82. 